\title{
Implications for nursing care concerning children discharged from a neonatal unit with chronic conditions*
}

\author{
Implicações para o cuidado de enfermagem de egressos de unidade neonatal com condições \\ crônicas
}

Tatiana Silva Tavares ${ }^{1}$, Roseni Rosângela de Sena ${ }^{1}$, Elysângela Dittz Duarte ${ }^{1}$

\begin{abstract}
Objective: to understand the implications for nursing care of children discharged from the neonatal intensive care with chronic conditions. Methods: a qualitative study of 14 mothers of children with chronic conditions. Individual interviews and Inventory of Pediatric Evaluation of Disability were conducted. Data submitted to thematic content analysis. Results: it was found that chronic conditions have determined the need for continuous care, varied complexity and more often than usual for children at home, in the community and network services. There were situations experienced by mothers in the care of daily life that should be considered by nurses in practice. Conclusion: the specific needs of these children require greater integration and training of nurses for the health education of caregivers, the shared home care and management in primary care, in order to facilitate the adaptation and family welfare, aimed at providing continuity of care.

Descriptors: Chronic Disease; Disabled Children; Pediatric Nursing; Family Nursing; Primary Care Nursing.
\end{abstract}

Objetivo: compreender as implicações para o cuidado de enfermagem de crianças egressas de terapia intensiva neonatal com condições crônicas. Métodos: estudo qualitativo com 14 mães de crianças com condições crônicas. Realizou-se entrevista individual e Inventário de Avaliação Pediátrica de Incapacidade. Dados submetidos à análise de conteúdo temática. Resultados: identificou-se que as condições crônicas determinaram a necessidade de cuidados contínuos, de complexidade variável e em maior frequência que o usual pelas crianças no domicílio, na comunidade e na rede de serviços. Verificaram-se situações vivenciadas pelas mães no cotidiano de cuidado que devem ser consideradas por enfermeiros na prática. Conclusão: as especificidades das necessidades dessas crianças requerem maior inserção e capacitação dos enfermeiros para a educação em saúde de cuidadores, o cuidado compartilhado no domicílio e o gerenciamento do cuidado na atenção primária, de forma a favorecer a adaptação e o bem-estar da família, visando continuidade do cuidado.

Descritores: Doença Crônica; Crianças com Deficiência; Enfermagem Pediátrica; Enfermagem Familiar; Enfermagem de Atenção Primária.

\footnotetext{
*Extracted from the dissertation "A continuidade do cuidado às crianças com condições crônicas egressas de terapia intensiva neonatal: a perspectiva das famílias", Universidade Federal de Minais Gerais, 2012.

${ }^{1}$ Universidade Federal de Minas Gerais. Belo Horizonte, MG, Brasil. 


\section{Introduction}

Scientific and technological progress in health care in recent decades allowed to decrease mortality of children with serious health problems, but caused increased morbidity and long-term disabilities. This epidemiological trend is evidenced mainly by increased survival of newborns with congenital or perinatal problems, which are in intensive care units $^{(1-2)}$. There is an increased risk for the newborns to develop chronic conditions in their childhood ${ }^{(2)}$.

The definition of chronic condition adopted in childhood includes conditions with biological, psychological or cognitive basis that lasted or have the potential to last for a year, producing one or more of the following effects: limitations of function, activity or social role compared to children of the same age without alterations in growth and development; dependence of compensatory mechanisms such as medicines, food and special technological devices or care because of the limitations of functions; need or use of services above the usual for the age, such as health services or education. These conditions influence the needs of these children, who are part of a larger group designated by children with special health care needs, which includes those with chronic conditions and at risk for developing them ${ }^{(3)}$.

Investments in neonatal units, which allow the survival of newborns, trigger the need for monitoring the growth and development that allows promoting health, preventing health problems and treating them in due course, to ensure their quality of life. However, an integrative review concerning children from neonatal intensive care units demonstrated restricted access to health services, low integration and superficial relationship between professionals and users ${ }^{(4)}$.

The care of children with special needs at home has been characterized in a national study as of a continuous and complex nature, permeated by knowledge and practices that do not belong to the daily lives of caregivers, usually mothers and grandmothers, which sets challenges for the family ${ }^{(5)}$. However, in an integrative review of international studies, it was found the lack of evidence on nursing interventions aiming at providing care for children with chronic conditions and their families ${ }^{(1)}$.

Therefore, it is evident that the health needs presented by these children require changes in organizing health care and nursing work process in order to ensure continuity of care after hospital discharge. The continuity is related to the care provided by health professionals over time, focusing on the individual experience of the user of integration and coordination of services and three types can be distinguished: informational, managerial and relational ${ }^{(6)}$.

In this context, it is necessary to explore the reality experienced by families of children with chronic conditions in the care searching for information that supports the work process of nursing professionals in order to ensure continuity of care after hospital discharge. This study is a secondary analysis, aiming at understanding the implications for the nursing care of children discharged from the neonatal intensive care units with chronic conditions.

\section{Methods}

It is a qualitative study. The approximation of reality was driven by of reference of dialectics for social criticism, considering the way the family takes care of the child, to meet their needs, and it is related to its historical and social insertion ${ }^{(7)}$. This study is a secondary analysis of data from a study that aimed at analyzing the continuity of care for children with chronic conditions, discharged from a neonatal intensive care unit of a philanthropic hospital in Minas Gerais, Brazil, to meet their care needs under the perspective of the family member responsible for care. Substantial information regarding the daily care to children with chronic conditions were obtained in the primary study by families, providing opportunity to conduct an analysis related to the implications for nursing care in the context of continuity. Therefore, the 
description of the scenario, participants and primary study data collection instruments are presented, then the procedures for secondary analysis.

The inclusion criteria for the participants were to be the primary caregiver of children with chronic conditions, discharged from an intensive care unit of a hospital in Minas Gerais, Brazil. The choice of these participants was due to its proximity to the child and ability to provide the information necessary for the study. The identification of these children was carried out from their documentary retrospective analysis of medical records in one year (01/02/2010 to 31/01/2011). Then the Questionnaire for Children Identification of Chronic Conditions was applied, revised by telephone calls with the family member who showed to be the child's primary caregiver. The questionnaire is a tool for identifying children with chronic conditions, based on the concept of chronic condition adopted $^{(3)}$, suitable to be used through telephone calls. It was developed by researchers linked to the Albert Einstein College of Medicine in New York, and translated and adapted to Portuguese of Brazil, by Brazilian researchers. After confirming the chronic condition of 20 children, an invitation to the primary caregiver was sent to participate. For two families, it was not possible to have access to their homes, two expressed unavailability of time and two refused to participate.

Fourteen mothers of children with chronic conditions participated in the survey. The study was made in Belo Horizonte, Brazil, and in five counties of the metropolitan area, where the participants lived. Home visits took place between March and May 2012. It was performed by the individual interview was made with the mothers by the researcher in their homes, with an average duration of 45 minutes recorded by audio digital recorder. In all the interviews the researcher, the participant and the child with chronic condition were present. The interview was guided by a semi-structured script, with questions about the socio-demographic data of the family, understanding their perspective and experience in relation to children's needs and meeting these needs for services. The script was previously tested to verify compliance with the purpose of the study. The interviews were transcribed and reviewed as to its accuracy in relation to the audios. The names of the participants and their children were replaced by the letters $\mathrm{M}$ and $\mathrm{F}$, respectively, followed by numerical identification referring to the order in which the interviews were conducted and the order of appearance of the speech fragment in the interview (eg. M3- 69).

The Inventory of Pediatric Evaluation of Inability was made through structured interviews with mothers, with an average of 30 minutes to characterize the effects of chronic conditions in the functionality of children. The instrument is suitable for evaluation of children from six months to seven years and a half, considering the expected performance for the age of Brazilian children in the same age group with no changes in growth and development. The inventory consists of three parts, with information about the child's functional performance in daily activities, caregiver assistance to the child in the activities and the necessary changes in the physical environment ${ }^{(8)}$.

Content analysis ${ }^{(9)}$ was made by means of successive readings of the transcripts set out to identify significant statements, considering the purpose of the secondary analysis. Excerpts of selected transcripts to compose this analysis were validated by two other researchers. Then, they proceeded to the description and analysis in the light of theoretical reference and the knowledge concerning the theme. The data obtained through the inventory were analyzed according to the procedures proposed in the Manual of the adapted Brazilian version $^{(8)}$.

The study complied with the formal requirements contained in the national and international regulatory standards for research involving human beings. 


\section{Results}

Mothers were presented as primary caregivers of all children with chronic conditions of the study. They were aged between 19 and 47 years, with an average of 31 years. Of the 14 women, two had incomplete grade school, six had complete grade school and six had complete high school. Eleven women lived with a partner. The number of children ranged between one and three. Nine women reported to devote themselves, at the time of the interview, to the household chores and the care of children, and the others had paid work outside the home. The household income ranged from 1.0 to 6.4 minimum wages (2.5 average wages), and at the time of the interview it was $\mathrm{R} \$ 622,00$ corresponding to US $\$ 334.00$ Five mothers received the Continued Benefit three obtained the use of gratuity benefit of public transport and four paid health insurance for the child.

The children had their ages corrected from 14 months to 23 months, with an average of 18 months. It is noteworthy that the correction of the chronological age was carried out, according the gestational age at birth, to allow assessment of child development without underestimating the development of preterm infants (seven children). They had the following health problems: F1 Down syndrome and respiratory problems; F2 hydrocephalus and malformation of the feet; F3 cerebral palsy and convulsive crisis; F4 microcephaly, cerebral palsy, asthma and strabismus; F5 developmental delay, bronchitis and strabismus; F6 adenoid hypertrophy; F7 hydrocephalus, cerebral palsy, bronchopulmonary dysplasia and allergy to cow milk; F8 developmental delay and bronchitis; F9 bronchitis; F10 bronchopulmonary dysplasia and strabismus; F11 developmental delay; F12 Down syndrome, and bronchospasm strabismus; F13 Down syndrome; F14 posterior cleft palate.

The repercussions of chronic conditions in children's needs were organized into three groups, according to the framework adopted for the study. It was found that ten children had limitations on the functions and structures of the body and carrying out activities, mobility impairments being checked in nine children. The dependence of compensatory mechanisms was observed in all children, including the use of more than one type in some cases ( 11 continuous use of medication, 7 type or different consistency of food, 8 use of technological devices). The participants reported care routinely performed by them as a result of the repercussions of chronic conditions such as medication administration, preparation and different consistency of the food provided for that age, food restriction, care with the ventricular-peritoneal valve, tracheostomy or gastrostomy, exercises for motor stimulation and speech, wearing glasses or cap, use of orthotics and care for the environment. Moreover, there was surveillance for changes in health status of children and the worsening signals.

Regarding the use of health services, 10 children were monitored by health professionals, in addition to the usual for their age, with nine out of care in health centers of Primary Health Care and ten in care in specialized services that offered care by medical specialists (neurologist, orthopedist, cardiologist, surgeons, pulmonologists, geneticists and homeopath) and rehabilitation (physical therapist, speech therapist and occupational therapist). The use of services from other sectors for child care was also identified, such as those of Social Services to obtain the Continuous Cash Benefit (six children) and the Free Pass for public transport (five children), education (two children) and Sports (one child), to promote development and facilitate socialization.

Concerning care at home and in the community, it was highlighted that the period immediately after discharge from the hospital was the most difficult to carry out the care at home, especially in the case of children depending on technology (F2 and F7 bypass peritoneal ventricular valve, F3 and F12 gastrostomy tracheostomy). The M3 statement revealed some of these difficulties: I knew what they had taught me, but did not know how to handle it here in the house, there at the Hospital, I did not bathe her, I was afraid of the probe and it was on the nose, when I 
went home she became worse, how I was going to bathe this girl, the gastric probe bigger than her ... I with the feeding, put a nail there, placed the device and the thing got clogged, I was terrified, gosh, it was very difficult to get used to that (M3-69).

According to M3, the initial difficulties were overcome through telephone contact and care with nurses and the hospital surgeon. The mothers of children depending on technologies reported having received information about the hospital care, but three could not accomplish it before discharge of the children and expressed insecurity to develop it at home. Different situation was reported by M12 who received guidelines and discharge obtained only after she demonstrated security to perform the tracheotomy care.

Adaptations in the administration of medications prescribed by professionals were made by mothers, being justified by them by participating in other activities that made it impossible to maintain the initial time, to preserve the child's sleep schedule, for fear that the child would become dependent on the drug, according to the observation of changes in the child's condition and longer duration of medication, as revealed by M9: Actually, it is to use every day [Clenil], only I'm afraid it can be addictive. Then I use every eight hours, I make his application, which I think it was every four hours (M9-64). The mothers mentioned adequacy of supply, with supply of certain food even facing some type of restriction or administration in order to make this care also pleasurable, as reported by M3: The speech therapist just cannot know that my daughter eats sweet. She is fed only by gastric tube, so I put in her mouth for her to feel and she loves it! (M3-40).

Regarding the care in health services, mothers reported about the limited integration between professionals and services, leaving them to inform the health professionals the child's health condition, taking reports and exams. Knowledge of the history of the children and the broad understanding of the needs of the professionals were determinant for them to trust and to remain with the same health professional.

Mothers considered that the care provided has quality when it is performed with detailed physical examination and discussion about the child's health status. They also valued: the availability to understand or hold procedures to enable assistance; recognition and meet their demands; and positivity in relation to the child's condition. As reported by M1: They were always very considerate [at the Health Center]. The girls [health professionals] themselves, if there was no doctor, they found a way, if it's not to go there, they called the ambulance and went to another place (M1-35).

Mothers revealed strategies to overcome the difficulties related to access to care, tests, technological devices, drugs and supplies for care in the healthcare industry. It was found that some mothers have decided to purchase health plans. Although the concerns of mothers have shown that to contemplate the different needs of these children other sectors of society are fundamental, such as social assistance, education, sports and leisure, not always access and use of services were possible. It was highlighted that there was hindering, misinformation about their rights, services and benefits available and the procedures to obtain them.

Prioritizing the care of children with chronic conditions was expressed by mothers, devoting little time to care of themselves. Social support from family and friends was important to take care of the child when the mother had to leave, to provide financial assistance and housing. Whenever existing, the contribution of such support to enable care routine at home and in the community was mentioned by the participants.

\section{Discussion}

The results of the characterization of the children showed that they have continuing care needs of varying complexity and more often than usual for children of the same age. It is noteworthy that the care was conducted and managed by the family, especially by mothers who have low levels of education and income. The reports of mothers indicate possibilities for nursing care within the health services, the 
community and the home, especially involving education, care and management actions, and the socioeconomic conditions of these families must be considered in the development of these actions.

The data contribute to the knowledge of nursing, since the reference of continuity of care brought to light the challenges faced by mothers to home care after discharge. In their reports the hospital discharge and the presence of nurses or other health professionals assisting the children at home were not mentioned to identify and meet their needs and the needs of their families. In addition, the above mentioned experiences made possible to seize the fragmentation of care provided by professional services. Therefore, the results show the urgent need to reflect on the implications of chronic conditions in childhood for nursing care and indicate actions to be incorporated in nursing practice, especially in primary care, in order to ensure the integrity and continuity of care to these children.

An important dimension of reflection refers to the ethical and legal responsibilities for nurses related to the complex care required by these children, such as those to be performed daily by mothers of children dependent on technologies to sustain life. Another dimension is related to the future prospects of children with permanent dependency of care throughout life, maintaining care of the family should be considered, in a context in which it is not adequately supported by services.

The transition to home, after hospital discharge, was indicated as a critical phase for family care, the difficulty in performing care in that period was reported by mothers. It has been found that the use of medications, special food and technological devices and as well as the risk of acute exacerbations, make home care more complex. Care environment different from hospital structure require the creation of a new way of doing.

Although the hospital provides opportunities for mediation of knowledge and practices ${ }^{(10)}$, this was not observed in the population studied. It recognizes the importance of the nurse's role in the family preparing for discharge and transition to home, contemplating guidance and support for the family to take care of essential actions to meet the needs of children and concerning the points in acute exacerbations. In order to continue care, the caregiver needs to acquire knowledge and carry out activities in this domain and in the area of practice, nursing actions for health education are essential ${ }^{(1,5,10-12)}$.

The mothers' statements on the adjustments made in the care developed at home proposed by professionals demonstrate that they had insufficient knowledge about the action and adverse reactions of drugs in their children and consequently the implications of changes in prescriptions. Lack of knowledge of such nature can cause uncertainty and adversely affect the continuity of care ${ }^{(12-13)}$, which was observed regarding the reduction of drug dosing frequency. Understanding the scientific technical content is essential for the family to make choices and participate in child care decisions with autonomy and safety ${ }^{(12-13)}$, so it is essential to adapt the information to the caregivers, especially seeking to understand whether the information was perceived.

It must be considered that the adjustments made at home by caregivers may interfere in with the expected results of the proposed actions and, consequently, the child's health condition. In this sense, recognizing that families make different arrangements for care, nurses should seek to adapt the treatment plan to the particularities of families, seeking to meet the children's needs and providing opportunities for experiences that allow them to live their childhood. Thus, professionals should give opportunity for caregivers to express what is feasible to carry out daily and their questions about the care plan. Furthermore, it is suggested that nurses seek to know how the daily care is provided and if the family can regularly get the necessary supplies.

Parents, in addition to ensuring the health and safety of the child, seek to ensure that they have a good life ${ }^{(13)}$, which allows the individualization of care, 
as revealed in this study by M3 to provide pleasure to the child, through the stimulus of taste. Professionals should develop a shared care plan, aimed at health promotion, not restricting the child's approach to maintaining and restoring the functioning of the body in the implementation of care.

The results showed the stress of mothers initiated by the care of her child with chronic condition, a fact also identified in other studies ${ }^{(1,11)}$. Stress is initially related to the feeling of fear and doubt about the ability to perform care, and after a period, the care provided continuously and comprehensively. The incorporation care process at home produces changes in family routine, affecting the coexistence of its members ${ }^{(14)}$. In addition, the financial difficulties in obtaining necessary supplies for child care and for transportation to health centers generate concern, especially when it is necessary for the mother to decrease or quit the job to accompany the child on visits and hospitalizations ${ }^{(11)}$. The primary caregiver is susceptible to overload of activities and vulnerable to illness, which can impair the continuity of care.

To cope with the chronic condition of the child and the reduction of the burden on the caregivers, the importance of social support from family and friends, is highlighted as mentioned by the mothers in the study. The family must rely on social support networks to help them to face the situation and to meet their needs as well the child's needs, such as groups of support and education in health ${ }^{(5)}$. The use of psychosocial interventions in primary care was suggested to favor family adaptation, and can meet the need of families who need more support due to the lack of resources, accumulation of stressors and negative perceptions ${ }^{(15)}$.

The proximity of the teams of primary care of the reality of the families enables an expanded grasp of their needs ${ }^{(14)}$, however, it is important that professionals have been prepared to contemplate the needs of these children in their practice. Studies have shown that although the performance of these professionals is powerful to establish development actions of family care, due to their link, health professionals have theoretical and technical weaknesses to meet the specific needs of these children, and must review their training to better provide assistance to them ${ }^{(14,16)}$.

Home visits or telephone calls can be used to promote safety and autonomy of the caregiver; however, they were only observed in the case of FM3. These strategies allow answering questions, identifying early complications, promote efficient use of supplies and prevent re-hospitalizations ${ }^{(10)}$. Thus, it is appropriate that the nursing work process in primary care and care management should be guaranteed to these children and considered strategies that can facilitate this process. The case management favors the continuity of care, improving caregiver skills. The approach includes identifying cases, needs assessment, development of an individualized planning, monitoring and evaluation of actions ${ }^{(17)}$.

The statements of the mothers allowed comprehending the professional service aspects in health services that promote relational and informational continuity, as the host and the link in the relationship and the flow of information about the children, for example, with the use of the statements. However, the occurrence of these aspects is timely, depending on the professional initiative and its interaction with the mother, which was also evidenced by another study that stressed the importance of hosting, link and shared decisionmaking ${ }^{(18)}$. In general, professionals define behaviors isolated, without a shared care plan and the guarantee of continuity of information depends on the role of mothers. These data reveal similar experience to parents of children with chronic conditions who participated in a study of continuity in Canada ${ }^{(6)}$.

Mothers mentioned the difficulty of obtaining drugs, technological devices and other supplies to care; access to monitoring and tests in specialized health services and care services in other sectors, which undermines continuity. For the parents of a Canadian study, the notion of managerial continuity can be extended beyond the provision of services, 
including planning and the necessary information to ensure the child's health in a broader sense, aiming at the quality of life. However, it was concluded that the ideal of management continuity for the family is contradicted by structural, procedural and attitudinal aspects, within and among services, which make up a reality of compartmentalized services ${ }^{(6)}$.

These results indicate the nurse's urgency to host these families, recognize their needs, plan care that meets the family context, perform forecasting and provision of supplies, guide on the resources of the network of services and seek mechanisms for the integration between the points of the network of different sectors. Professionals should invest in instruments that allow the recording and sharing of technical information on assistance rendered among the points of care ${ }^{(14)}$. The coordination of care can make it more efficient to ensure quality of life for children with chronic conditions, also allowing reducing the emotional and financial costs for the family.

The study was made with a population discharged from a health unit, with similar socioeconomic profile and belonging to a limited geographical region. Therefore, it is necessary to observe the information concerning the population and the study setting in the use of the results because they represent this unique reality.

\section{Conclusion}

It was found that the specific needs of children with chronic conditions require greater insertion and training of nurses in the care of these children and their families in many areas, especially in the transition to home after discharge. Whereas care for children with chronic conditions is performed and managed by the family, especially the mother, most of the time, it is essential that nursing favors adaptation and their own well-being for the viability of long-term care.

\section{Collaborations}

Tavares TS contributed to the project design, analysis and interpretation of data, writing the article and final approval of the version to be published. Sena RR and Duarte ED contributed to the project design, analysis and interpretation of data, relevant critical revision of the intellectual content and final approval of the version to be published.

\section{References}

1. Rehm RS. Nursing's contribution to research about parenting children with complex chronic conditions: an integrative review, 2002 to 2012. Nurs Outlook. 2013; 61(5):266-90.

2. Hack M, Schluchter M, Andreias L, Margevicius S, Taylor HG, Drotar D, et al. Change in prevalence of chronic conditions between childhood and adolescence among extremely low-birth-weight children. JAMA. 2011; 306(4):394-401.

3. Stein RE. The 1990s: a decade of change in understanding children with ongoing conditions. Arch Pediatr Adolesc Med. 2011; 165(10):880-3.

4. Custodio N, Abreu FCP, Marski BSL, Mello DF, Wernet M. Alta da unidade de cuidado intensivo neonatal e o cuidado em domicílio: revisão integrativa da literatura. Rev Min Enferm. 2013; 17(4):984-91.

5. Neves ET, Silveira A, Arrué AM, Pieszak GM, Zamberlan KC, Santos RP. Network of care of children with special health care needs. Texto Contexto Enferm. 2015; 24(2):399-406.

6. Miller A, Condin C, Mckellin W, Shaw N, Klassen A, Sheps S. Continuity of care for children with complex chronic health conditions: parent's perspectives. BMC Health Serv Res [Internet]. 2009 [cited 2016 Mar. 13]; 9(242):1-11. Available from:http://bmchealthservres.biomedcentral. com/articles/10.1186/1472-6963-9-242

7. Gelbcke FL, Peña, YF, Gallo E. Dialéctica y materialismo histórico: su aproximación al estudio del fenómeno salud/enfermedad. In: Prado ML, editor. Investigación cualitativa en enfermería: contexto y bases conceptuales. Washington: Organización Panamericana de La Salud; 2008. p.147-75. 
8. Mancini MC. Inventário de Avaliação Pediátrica de Incapacidade (PEDI): manual da versão brasileira adaptada. Belo Horizonte: UFMG; 2005.

9. Bardin L. Análise de conteúdo. São Paulo: Edições 70; 2015.

10. Oliveira SR, Sena RR. A alta da unidade de terapia intensiva neonatal e a continuidade da assistência: um estudo bibliográfico. Rev Min Enferm. 2010; 14(1):103-9.

11. Guerini IC, Cordeiro PKS, Osta SZ, Ribeiro EM. Relatives' perception regarding the stressors resulting from the care demands of technologydependent children and adolescents. Texto Contexto Enferm. 2012; 21(2):348-55.

12. Rodrigues PF, Amador DD, Silva KL, Reichert APS, Collet $\mathrm{N}$. Interação entre equipe de enfermagem e família na percepção dos familiares de crianças com doenças crônicas. Esc Anna Nery. 2013; 17(4):781-7.

13. Woodgate RL, Edwards M, Ripat JD, Borton B, Rempel G. Intense parenting: a qualitative study detailing the experiences of parenting children with complex care needs. BMC Pediatr [Internet]. 2015 [cited 2016 Mar. 13];15:197. Available from:http://bmcpediatr.biomedcentral.com/ articles/10.1186/s12887-015-0514-5
14. Sousa EFR, Costa EAO, Dupas G, Wernet M. Continued care for families of children with chronic diseases: perceptions of family health program teams. Rev Esc Enferm USP. 2013; 47(6):1367-72.

15. Hall HR, Neely-Barnes SL, Graff JC, Krcek TE, Roberts RJ, Hankins JS. Parental stress in families of children with a genetic disorder / disability and the resiliency model of family stress adjustment and adaptation. Issues Compr Pediatr Nurs. 2012; 35(1):24-44.

16. Duarte ED, Silva KL, Tavares TS, Nishimoto CLJ, Walty CMRF, Sena RR. Challenges of nursing care for children with chronic conditions in primary health care. Esc Anna Nery. 2015; 19(4):648-55.

17. Freund T, Kayling F, Miksch A, Szecsenyi J, Wensing M. Effectiveness and efficiency of primary care based case management for chronic diseases: rationale and design of a systematic review and meta-analysis of randomized and nonrandomized trials. BMC Health Serv Res [Internet]. 2010 [cited 2016 Mar. 13];10:112. Available from: http://bmchealthservres.biomedcentral.com/ articles/10.1186/1472-6963-10-112

18. Schimith MD, Brêtas ACP, Budó MLD, Simon BS, Leal TC, Backes DM. Continuity of care in the Health Care Network: negotiation between users and professionals. Rev Rene. 2014; 5(5):812-22. 